\title{
The energy cost of playing active video games in children with obesity and children of a healthy weight
}

\section{O'Donovan', E. F Roche ${ }^{2}$ and J. Hussey ${ }^{1}$}

${ }^{1}$ Discipline of Physiotherapy, School of Medicine, Trinity Centre for Health Sciences, Dublin, Ireland; ${ }^{2}$ School of Medicine, Trinity Centre for Health Sciences, Dublin, Ireland

Received 11 January 2013; revised 25 February 2013; accepted 18 March 2013

\section{What is already known about this subject}

- Active video games (AVGs) are being marketed as exercise tools.

- AVG play can result in light-to-moderate intensity physical activity.

\section{What this study adds}

- A comparison correcting for body size between the energy expended by children with obesity and those of a healthy weight playing AVGs.

- An examination of several variables related to the energy cost of AVG play including steps taken and rate of perceived exertion.

- There may be some differences in how children with obesity and children of a healthy weight play AVGs.

\section{Summary}

Background: Increasing physical activity and reducing sedentary behaviour form a large part of the treatment of paediatric obesity. However, many children today spend prolonged periods of time playing sedentary video games. Active video games (AVGs) represent a novel and child friendly form of physical activity.

Objectives: To measure the energy cost of playing two AVGs in children with obesity and healthy age- and gender-matched children.

Methods: The energy cost of gaming and heart rates achieved during gaming conditions were compared between groups.

Results: AVG play can result in light-to-moderate intensity physical activity (2.7-5.4 metabolic equivalents). When corrected for fat-free mass those with obesity expended significantly less energy than healthy weight peers playing Nintendo Wii Fit Free Jogging $(P=0.017)$. No significant difference was seen between groups in the energy cost of playing Boxing.

Conclusion: Certain AVGs, particularly those that require lower limb movement, could be used to increase total energy expenditure, replace more sedentary activities, or achieve moderate intensity physical activity among children with obesity. There seems to be some differences in how children with obesity and children of a healthy weight play AVGs. This could result in those with obesity expending less energy than their lean peers during AVG play.

Keywords: Active video games, energy expenditure, moderate exercise. 


\section{Introduction}

Many children today spend prolonged periods of time playing sedentary video games $(1,2)$. This is a cause for concern because sedentary activity is associated with increased body mass index (BMI) and other health problems in children $(3,4)$. Active video games (AVGs), however, can be considered a form of physical activity (5), and indeed many promote a healthy lifestyle image (6). Children with obesity have been shown to be less likely than healthy weight children to participate in traditional exercise or sports (7), and spend more time in sedentary activities such as television viewing and computer gaming (8). It is recommended that all children accumulate at least $60 \mathrm{~min}$ of moderate intensity activity a day. Furthermore, the World Health Organization recommends reducing inactivity in obese children (9). However, children value screen time $(10,11)$, and the popularity of video games is increasing (1). There is therefore a clear need for health professionals to capitalize on the positive engagement children may have with video games in order to increase physical activity levels or reduce sedentary behaviours. AVGs may represent a child-friendly novel exercise tool for children with obesity.

A limited number of studies have compared the energy cost of AVG play in children with an increased BMI to children of a healthy weight; however, these have grouped those who are overweight and obese together, disabling a comparison between those with obesity and those of a healthy weight. Unnithan et al. (12) and Bailey and Mclnnis (13) reported that playing a dance video game required moderate intensity activity, as children reached a mean of 3.2 and 5.4 metabolic equivalents (METs), respectively. Lanningham-Foster et al. (14) and Mitre et al. (15) found AVG play to require light intensity physical activity. When corrected for fat-free mass (FFM), Unnithan et al. (12) found no significant difference in the energy cost of AVG play between children who were overweight and those who were lean. These results were echoed by Lanningham-Foster et al. $(14,16)$ and by Penko and Barkley (17). However, differences were seen by Mitre and colleagues (15) whereby lean participants expended more energy when corrected for FFM, and by Bailey and McInnis (13) who reported that overweight and obese participants expended more energy during gameplay than participants of a healthy weight. In children, physiological variables during exercise are related to body size (18). Of the studies reported above, only Unnithan et al. (12) reported having tested that the unit of energy expenditure was adequately corrected for body size between groups of children.

The aims of this study were to measure the energy required in playing AVGs among children with obesity and those of a healthy weight, to compare results to recommended guidelines for moderate activity (3-6 METs), and to compare the oxygen consumption $\left(\mathrm{VO}_{2}\right)$ and heart rate $(\mathrm{HR})$ response to gaming between children with obesity and children of a healthy weight.

\section{Methods}

Design and recruitment

A cross-sectional design was used. Children were recruited from a paediatric weight management outpatient clinic and schools in Dublin. Children eligible to take part were aged between 7 and 17 years, had completed the Physical Activity Readiness Questionnaire (19), and provided written informed assent and written informed consent from parents or guardians. Those with cardiac, infectious, neuromuscular, musculoskeletal or rheumatologic conditions exacerbated by exercise were excluded. Smokers and those taking prescribed medication other than the oral contraceptive pill were excluded. This study was conducted in accordance with the Declaration of Helsinki (2008) (48). Ethics approval was granted by the Research Ethics Committee of St. James's Hospital/The Adelaide and Meath Hospital Dublin, incorporating the National Children's Hospital.

\section{Measurements}

Weight was measured to the nearest $0.1 \mathrm{~kg}$, and height to the nearest complete $1 \mathrm{~mm}$ using a Seca scales and stadiometer, respectively (Seca Mod 220, Hamburg, Germany). BMI z-scores were calculated as per WHO (2007) data using software developed by Pan and Cole (LMS software, Health for all Children. Harlow Healthcare, Harlow Printing Limited) (49). Cutoff points used were percentiles that matched the adult cut-offs of a BMl of 25 and 30 at age 18 years. Only children considered obese according to these guidelines were recruited into the obese group. Only children considered to be of a healthy weight were recruited into the control group. Skinfold measurements were taken at the triceps, biceps, subscapular and suprailiac sites to the nearest $0.1 \mathrm{~mm}$ according to standardized guidelines (20). Results were used to estimate body fat percentage (21).

The six-minute walk test was performed as described by the American Thoracic Society to ensure all participants were given the same standardized instructions (22). $\mathrm{VO}_{2}$, kilocalories expended 
Table 1 Participant characteristics

\begin{tabular}{lccc}
\hline Variable & $\begin{array}{l}\text { Those with obesity } \\
\text { Mean (SD) }\end{array}$ & $\begin{array}{l}\text { Lean controls } \\
\text { Mean (SD) }\end{array}$ & $\begin{array}{l}\text { Significance } \\
P \text {-value }\end{array}$ \\
\hline Age, years & $12(3)$ & $12(3)$ & 0.898 \\
BMl, kg m²* & $29.72(5.16)$ & $18.68(2.41)$ & 0.000 \\
BMl for age z-score* & $2.79(0.61)$ & $0.17(0.71)$ & 0.000 \\
Fat-free mass, \%* & $39(18)$ & $15(9)$ & 0.000 \\
Fat-free mass, kg* & $47.96(11.87)$ & $33.06(9.32)$ & 0.000 \\
6MWT distance, m $^{*}$ & $483.0(82.6)$ & $552.2(85.4)$ & 0.004 \\
\hline
\end{tabular}

Results are expressed as mean (SD); 6MWT, six-minute walk test; kg, kilogram; m, metre, BMI, body mass index. *indicates a statistically significant difference between groups. (kcal) and HR were measured at rest and while playing AVGs using an indirect calorimeter (Oxycon Mobile, Jaeger, Viasys Healthcare, Hoechberg, Germany) and a Polar HR monitor. The Oxycon Mobile is a lightweight portable system which communicates telemetrically with the Polar HR monitor and laboratory computer to give details on $\mathrm{VO}_{2}$, energy expenditure and related cardiorespiratory parameters on a breath-by-breath basis. The Oxycon Mobile has been validated $(23,24)$ and used in similar studies (25).

AVGs used were Wii Sports Boxing and Wii Fit Free Jogging (hereafter referred to as Boxing and Jogging, respectively). After 15 min of rest in supine, participants played each game for $15 \mathrm{~min}$ with at least a 5-min seated rest between games or until HR returned to resting values. Participants were entered as guest players to ensure that all started at the same basic level. Participants wore validated pedometers (26) on each ankle during gaming conditions (Stepwatch, Orthocare Innovations, Washington, USA). Perceived exertion was rated immediately after each game using the 10-point ONMI rate of perceived exertion scale $(27,28)$.

\section{Statistical analysis}

METs were calculated for each individual as gaming $\mathrm{VO}_{2}$ divided by resting $\mathrm{VO}_{2}$. Age-predicted maximal HR was calculated as $208-\left(0.7^{\star}\right.$ age $)(29,30)$. Pedometer data from the last 10 min of gameplay, when children had become accustomed to the movements required to play the game, were used in analysis. To reduce any effect of leg dominance, data from both legs were averaged for each participant for each game. $\mathrm{VO}_{2}$ and $\mathrm{HR}$ were averaged over the final 5 min excluding the last minute of each condition to ensure a steady state was reached. Energy expended in kilocalories was summed for the entire duration of each condition to give a realistic measure of the kilocalories expended during an active video gaming session including transition periods.
Ratio methods were used to ensure that energy expenditure was expressed in a unit independent of body size when comparing between groups. Where ratio methods did not correct for body mass, linear regression scaling was conducted (31). Data for all studies were analyzed with the Statistical Package for Social Science (SPSS) version 16.0.1 (IBM, New York, USA). For continuous variables, normal distribution was assessed by examining measures of central tendency, skewness relative to its standard error, and a Kolmogorov-Smirnov test was carried out with $P>0.05$, indicating that data were normally distributed. Where data were skewed, natural log transformations were employed. Single sample $t$-tests were conducted to compare the energy cost of gaming with the lower recommended cut-off value for moderate intensity activity ( 3 METs and 64 \%HRmax) (32). Differences between conditions and groups were analyzed using a mixed-design analysis of variance (ANOVA) with group as a betweengroups factor and condition as the within-groups factor. Difference in rate of perceived exertion between groups was assessed using a MannWhitney U-test.

\section{Results}

Thirty children with obesity (9 male, mean age 12 [3] years) and 30 age- and sex-matched lean children completed this study. Participant characteristics are detailed in Table 1.

\section{Comparison with guidelines for moderate intensity activity}

$\mathrm{HR}$ and $\mathrm{VO}_{2}$ recorded during rest and gaming conditions are presented in Table 2. HR data collected for one participant during Boxing and for two participants during Jogging (all lean controls) were insufficient to use in analysis due to poor contact between the HR monitor belt and skin. Data on steps taken during Boxing were skewed. Step data for Boxing 


\begin{tabular}{|c|c|c|c|}
\hline & Variable & $\begin{array}{l}\text { Those with obesity } \\
\text { Mean (SD) }\end{array}$ & $\begin{array}{l}\text { Lean controls } \\
\text { Mean (SD) }\end{array}$ \\
\hline \multirow[t]{3}{*}{ Rest } & $\mathrm{HR}, \mathrm{bpm}$ & $75(10)$ & $79(12)$ \\
\hline & $\mathrm{VO}_{2}, \mathrm{~mL} \mathrm{~min}^{-1}$ & 283.41 (52.26) & 244.64 (63.47) \\
\hline & kcal 15 min $^{-1}$ & $20.54(4.64)$ & $15.03(5.46)$ \\
\hline \multirow[t]{6}{*}{ Boxing } & \%HRmax & 63.01 (8.56) & $72.84(13.41)$ \\
\hline & $\mathrm{VO}_{2}, \mathrm{~mL} \mathrm{~min}^{-1}$ & 729.21 (280.81) & 698.99 (206.89) \\
\hline & METs & $2.72(0.68)$ & $2.99(1.03)$ \\
\hline & kcal 15 min $^{-1}$ & 50.36 (15.85) & 41.04 (15.44) \\
\hline & Ln steps taken & $3.44(1.20)$ & $3.96(1.14)$ \\
\hline & Steps taken & $57.8(65.2)$ & $81.6(61.8)$ \\
\hline \multirow[t]{6}{*}{ Jogging } & \%HRmax & 79.52 (10.02) & $78.83(9.11)$ \\
\hline & $\mathrm{VO}_{2}, \mathrm{~mL} \mathrm{~min}^{-1}$ & 1445.57 (499.46) & 1167.41 (387.59) \\
\hline & METs & $5.35(1.52)$ & $4.87(1.40)$ \\
\hline & kcal 15 min $^{-1}$ & $106.43(30.45)$ & 66.89 (23.90) \\
\hline & $\mathrm{VO}_{2} \mathrm{~mL} \mathrm{~min}^{-1} \mathrm{FFM}^{-1}$ & $29.93(7.01)$ & 34.87 (8.19) \\
\hline & Steps taken & $522.6(111.6)$ & 541.9 (75.0) \\
\hline
\end{tabular}

Table $2 \mathrm{HR}$ and $\mathrm{VO}_{2}$ response to rest and AVG play

bpm, beats per minute; FFM, fat-free mass; HR, heart rate; kcal, kilocalorie; Ln, natural log; MET, metabolic equivalent; min, minute; $\mathrm{mL}$, millilitre; $\mathrm{VO}_{2}$, oxygen consumption.

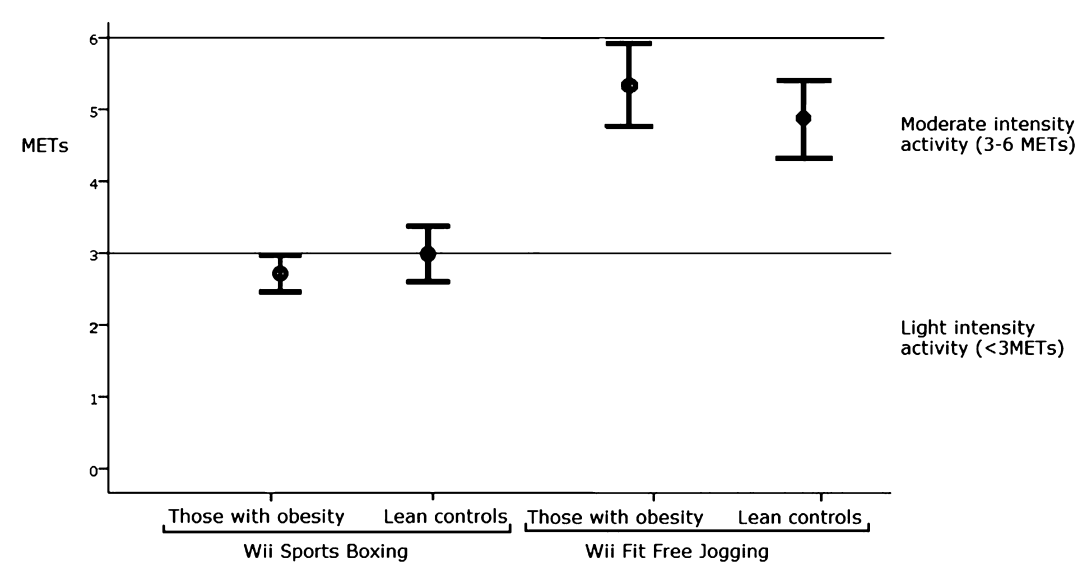

Figure 1 METs (metabolic equivalents) expended by each group represented graphically with guideline cut-off points for moderate activity. are therefore reported in absolute steps, and in natural log form (Table 2).

Mean METs reached by participants with obesity while Boxing were of a light intensity, and were statistically significantly lower than 3 METs (mean difference $-0.28, \mathrm{Cl}-0.54$ to -0.03 , Fig. 1). Mean METs reached by those of a healthy weight were at the threshold for moderate activity (Fig. 1), and were not statistically different from 3 METs (mean difference $-0.01, \mathrm{Cl}-0.39$ to 0.37). During Jogging, the energy expended by both groups was statistically significantly greater than the guideline lower threshold for moderate activity of 3 METs (Fig. 1). As evident from Fig. 1, Jogging resulted in MET levels that were significantly higher than those achieved during Boxing.

Among those with obesity, mean \%HRmax during Boxing was lower than $64 \%$ but was not statistically different from 64\% (mean difference -0.99, Cl -4.18 to $2.21 \%$ ). In non-obese participants, mean $\% H R m a x$ during Boxing was significantly higher than 64\% (mean difference 8.8, Cl 3.74-13.94). In both groups, the mean \%HRmax reached during Jogging was statistically significantly higher than 64\%. In those with obesity, the mean difference was 15.52\% (Cl 11.78-19.23). In those without obesity, the mean difference was 14.83\% (Cl 11.30-18.36).

\section{Comparison between groups}

A commonly used method to correct energy expended for body size is to divide by fat-free mass $\left(\mathrm{mL} \mathrm{min}^{-1} \mathrm{FFM}^{-1}\right.$ ) (33). When this was done, there was no significant correlation between energy expended during Jogging and body mass, indicating 
that the data were controlled for differences in body mass between groups. An independent $t$-test revealed that those with obesity expended significantly less energy expressed in $\mathrm{mL} \mathrm{min}^{-1} \mathrm{FFM}^{-1}$ than lean controls playing Wii Fit Free Jogging $(P=0.017)$.

Dividing energy expenditure by FFM did not correct Boxing or resting data for body size. Therefore, linear regression scaling was used. Assumptions of homogeneity of variance, homogeneity of regression, and homoscedasticity were not violated. The group effect on energy expended during Boxing in this model was insignificant $(F=3.252, P=0.077)$, indicating that there was no significant difference between groups in energy expended playing Boxing. The significance of a group effect on energy expended at rest was also insignificant $(F=0.774, P=0.383)$.

In repeated measures ANOVA with \%HRmax and steps taken as variables, a significant difference between groups was seen for \%HRmax reached during gaming conditions ( $F=5.66, P=0.021)$. Post hoc analysis revealed that there was a significant difference between groups for Boxing $(P=0.001)$, but not for Jogging $(P=0.784)$. Those with obesity reached a significantly lower \%HRmax during Wii Sports Boxing than those of a healthy weight. There was no significant difference between groups in the number of steps taken during gaming conditions, or the rate of perceived exertion during Boxing $(U=346, \quad P=0.120)$ or Jogging $(U=312, \quad P=$ 0.090).

\section{Discussion}

The aim of this study was to examine the energy cost of playing two AVGs in children with obesity and healthy weight controls. Playing Boxing was found to be a light intensity activity for both groups, while Jogging was a moderate intensity activity. Although some children expended above 3 METs while playing Wii Sports Boxing, the majority did not. This is similar to results from other studies on healthy children $(34,35)$, but differs from the results of studies on adult clinical populations $(36,37)$ and children with increased BMI (13). The variation associated with the energy cost of playing Wii Boxing and differences in populations recruited between studies is such that the population mean could lie just below, or just above, 3 METs. This may explain why some studies classified Boxing as a moderate intensity activity while others did not. In this study, a single sample $t$-test revealed that neither population reached an energy expenditure significantly greater than 3 METs during Boxing. Although 60 min of age-appropriate moderate-to-vigorous physical activity a day is a rec- ommended minimum for children to engage in, total energy expenditure is also important. Therefore, light intensity exercise, such as Boxing, could be encouraged among children with obesity, particularly to break up periods of sedentary activity. Wii Fit Free Jogging can be considered a moderate intensity activity in both populations examined.

Although absolute energy expenditure is used in exercise prescription, to compare energy expended between groups it was necessary to correct for body size (31). Dividing by FFM corrected the energy cost of Jogging for body mass. Linear regression scaling was required to correct the energy cost of Boxing for body mass. It is hypothesized that the same method of correcting for body size did not work for both Jogging and Boxing data because Jogging is a weight-bearing exercise, and as such energy expended playing this game would be expected to be more dependent on a player's body mass than Boxing, which predominantly requires upper limb movement. The same scaling may therefore not be appropriate for both activities (38).

Once corrected for body size, those with obesity expended significantly less than those without obesity during Jogging. During Boxing, although there was no significant difference between groups for energy expended, those with obesity reached a significantly lower \%HRmax than those of a healthy weight. There is evidence to suggest that those with obesity may not engage with physical activity as much as their lean peers (39). However, despite differences between groups in the HR response to gaming, there was no significant difference between groups in rate of perceived exertion. As rate of perceived exertion is thought to measure feelings of effort, discomfort and fatigue (32), this indicates that both groups put a similar amount of effort into gameplay. Furthermore, because there was no significant difference in the number of steps taken during gaming conditions between groups, differences in energy expended and HRs reached are unlikely to be as a result of the rate at which participants jogged on the spot or moved their lower limbs during Boxing. One hypothesis is that there may have been a difference in the height to which participants raised their knees during Jogging. Joint moments are known to be different between children with obesity and healthy weight children during various activities (4042). The tendency during stepping is for children with obesity to flex their knees less than those of a healthy weight (40). Furthermore, fast walking, which would have been an action similar in nature to playing Wii Fit Free Jogging, has been shown to result in less angular movement at the knee among children with 
obesity (41). During investigations into body movement during AVG play, movement differences between games were reported $(43,44)$. These differences were hypothesized to explain the variation in the energy cost of playing different AVGs. For example, Graves and colleagues (43) hypothesized that increased dominant arm movement seen during Wii Sports Tennis compared with Wii Sports Bowling may have explained the difference in the physiological cost of playing these games. It is therefore possible that movement differences between groups could account for the energy and HR differences seen in this study.

Clinically, it can be argued that accounting for differences in body size is not important because the whole child exercises and energy expenditure (or exercise intensity) uncorrected for body size is used in exercise prescription. To put results on the total energy cost of AVG play into perspective, a comparison can be made between the energy expended during each condition and $300 \mathrm{kcal}$. Provided energy intake remained constant, it would take the average child with obesity in this study 220 min of rest, 89 min playing Nintendo Wii Sports Boxing, or 42 min playing Nintendo Wii Fit Free Jogging to expend $300 \mathrm{kcal}$. If a child were to replace a sedentary activity such as television viewing with Wii Fit Free Jogging for $15 \mathrm{~min}$, the net increase in energy expenditure would be approximately $86 \mathrm{kcal}$.

A recognized limitation of this study is that pubertal stage was not assessed. Those with obesity are known to reach puberty before children of a healthy weight (45). Although the measurement of puberty would not have changed the main result of these studies, which was to determine the energy cost of playing AVGs, it may have informed between group comparisons. The fact that energy expended at rest did not differ significantly between groups when corrected for differences in body size suggests that puberty is unlikely to have impacted significantly on the energy cost of gaming, although it is worth noting that the extra muscle mass acquired during puberty may have allowed those at more advanced pubertal stages to play AVGs with greater vigour and consequently expend more energy. It is possible that wearing the calorimetric equipment itself may have interfered with the activity intensity; however, the chances of this were minimized through a familiarization period and the use of a lightweight portable calorimeter. Furthermore, any interference would have been as likely to occur in one group as the other.

An unavoidable limitation of this study was that an investigator was present during testing. It is possible that children played games in an active manner and maintained being active for the 15 min of gameplay due to the presence of an investigator and the laboratory environment (46). As a result, levels of energy expenditure reached may not reflect those that would be achieved in free-living condition. For example, when playing Wii Boxing, some children may have stayed standing as advised by on-screen instructions given before the game began, whereas in an unsupervised situation these instructions may be ignored and the game played in a seated position. Because the equipment used to measure energy expenditure required constant attention, it was not possible to avoid this limitation.

Results of this study could inform healthcare workers on the use of AVGs as exercise tools in a clinical or home situation. It is evident that playing AVGs is not a sedentary activity and could therefore be used as an alternative to more sedentary activities such as television viewing. Similar to other studies (47), this paper revealed that playing a lower limbcontrolled game requires more energy than playing an upper limb-controlled game.

Results of this study have shown that children with obesity and healthy weight children can expend light to moderate amounts of energy while playing AVGs. Overall, it can be concluded that playing Nintendo Wii Sports Boxing required light intensity energy expenditure among those with obesity. However, as it is widely agreed that some activity is better than none, playing Wii Sports Boxing can be encouraged over more sedentary pursuits such as playing traditional video games, and could theoretically result in health benefits through increasing total energy expenditure and decreasing sedentary time, both of which are important in the management of paediatric obesity (10). Playing Nintendo Wii Fit Free Jogging required moderate intensity energy expenditure in both groups and can therefore be considered towards the acquisition of 60 min of moderate activity recommended to children.

This was the first study to compare the energy cost of AVG play between children with obesity and children of a healthy weight. When corrected for body size, results showed that those with obesity expended significantly less energy (per unit FFM) during Wii Fit Free Jogging than those of a healthy weight; however, there was no significant difference between groups for energy expended playing Wii Sports Boxing. Because exercise is prescribed to the whole child, the absolute energy cost of AVG play is arguably more useful clinically and may inform the choice of exercise tools used to treat children with obesity. 


\section{Conflict of interest statement}

The authors declare no conflict of interests.

\section{Author contributions}

COD was involved in study design, data collection, data analysis, data interpretation, literature search and the generation of figures. ER was involved in the study design and data collection. $\mathrm{JH}$ was involved in the study design, data collection and data interpretation. All authors were involved in writing the paper and had final approval of the submitted and published versions.

\section{Acknowledgements}

Many thanks to the Irish Research Council for Science Engineering and Technology for funding this study.

\section{References}

1. Rideout VJ, Foehr UG, Roberts DF. Generation M2 Media in the Lives of 8-to-18-Year-Olds. The Henry J Kaiser Family Foundation: California, USA, 2010.

2. Williams JG, Doyle S, Harris E, et al. Growing up in Ireland National Longitudinal Study of Children, The Lives of 9-Year-Olds. The Stationary Office: Dublin, 2009.

3. Viner RM, Cole TJ. Television viewing in early childhood predicts adult body mass index. J Pediatr 2005; 4/147: 429-435.

4. Mark AE, Janssen I. Relationship between screen time and metabolic syndrome in adolescents. J Public Health (Oxf) 2008; 30/2: 153-160.

5. Daley AJ. Can exergaming contribute to improving physical activity levels and health outcomes in children? Pediatrics 2009; 124/2: 763-771.

6. Nintendo. 2012). American heart association and Nintendo join forces to promote healthy living. [WWW document]. URL http://www.nintendo.com/whatsnew/detail/ gfrla8wP7kqnwa_I2Y2uLYfAbO820FI6

7. Dowda M, Ainsworth BE, Addy CL, Saunders R, Riner W. Environmental influences, physical activity, and weight status in 8- to 16-year-olds. Arch Pediatr Adolesc Med 2001; 155/6: 711-717.

8. Hoos MB, Plasqui G, Gerver WJ, Westerterp KR. Physical activity level measured by doubly labeled water and accelerometry in children. Eur J Appl Physiol 2003; 89/6: 624-626.

9. Branca F, Nikogosian H, Lobstein T. The Challenge of Obesity in the WHO European Region and the Strategies for Response. World Health Organisation: WHO Regional Office for Europe, Copenhagen, Denmark, 2007.

10. Epstein LH. Integrating theoretical approaches to promote physical activity. Am J Prev Med 1998; 15/4: 257-265.
11. Epstein LH, Roemmich JN, Saad FG, Handley EA. The value of sedentary alternatives influences child physical activity choice. Int J Behav Med 2004; 11/4: 236-242.

12. Unnithan VB, Houser W, Fernhall W. Evaluation of the energy cost of playing a dance simulation video game in overweight and non-overweight children and adolescents. Int J Sports Med 2007; 27/10: 804-809.

13. Bailey BW, Mclnnis K. Energy cost of exergaming: a comparison of the energy cost of 6 forms of exergaming. Arch Pediatr Adolesc Med 2011; 165/7: 597-602.

14. Lanningham-Foster L, Jensen TB, Foster RC, et al. Energy expenditure of sedentary screen time compared with active screen time for children. Pediatrics 2006; 118/6: 1831-1835.

15. Mitre N, Foster RC, Lanningham-Foster L, Levine JA. The energy expenditure of an activity-promoting video game compared to sedentary video games and TV watching. J Pediatr Endocrinol Metab 2011; 24/9-10: 689-695.

16. Lanningham-Foster L, Foster RC, McCrady SK, Jensen TB, Mitre N, Levine JA. Activity-promoting video games and increased energy expenditure. J Pediatr 2009; 154/6: 819-823.

17. Penko AL, Barkley JE. Motivation and physiologic responses of playing a physically interactive video game relative to a sedentary alternative in children. Ann Behav Med 2010; 39/2: 162-169.

18. Rowland T. Human Kinetics, Children's Exercise Physiology. Champaign: Illinois, USA, 2005.

19. Thomas S, Shephard RJ. Revision of the Physical Activity Readiness Questionnaire (PAR-Q). Canadian Journal of Sports Sciences 1992; 17/4: 338-345.

20. Gore C. Human Kinetics, Physiological Tests for Elite Athletes. Champaign: Illinois, USA, 2000.

21. Durnin JV, Womersley J. Body fat assessed from total body density and its estimation from skinfold thickness: measurements on 481 men and women aged from 16 to 72 years. Br J Nutr 1974; 32/1: 77-97.

22. American Thoracic Society. ATS statement: guidelines for the six-minute walk test. Am J Respir Crit Care Med 2002; 166/1: 111-117.

23. Salier EJ, Rosdahl H, Schantz P. Validity of the Oxycon Mobile metabolic system under field measuring conditions. Eur J Appl Physiol 2012; 112/1: 345-355.

24. Rosdahl H, Gullstrand L, Salier-Eriksson J, Johansson P, Schantz P. Evaluation of the Oxycon Mobile metabolic system against the Douglas bag method. Eur J Appl Physiol 2010; 109/2: 159-171.

25. Hussey J, Bennett K, O Dwyer J, Langford S, Bell C, Gormley J. Validation of the RT3 in the measurement of physical activity in children. J Sci Med Sport 2009; 12/1: 130-133.

26. McDonald CM, Widman L, Abresch RT, Walsh SA, Walsh DD. Utility of a step activity monitor for the measurement of daily ambulatory activity in children. Arch Phys Med Rehabil 2005; 86/4: 793-801.

27. Robertson RJ, Goss FL, Aaron DJ, et al. Observation of perceived exertion in children using the OMNI pictorial scale. Med Sci Sports Exerc 2005; 38/1: 158-166. 
28. Utter AC, Robertson RJ, Nieman DC, Kang J. Children's OMNI Scale of Perceived Exertion: walking/running evaluation. Med Sci Sports Exerc 2002; 34/1: 139-144. 29. Tanaka H, Monahan KD, Seals DR. Age-predicted maximal heart rate revisited. J Am Coll Cardiol 2001; 37/1: 153-156.

30. Mahon AD, Marjerrison AD, Lee JD, Woodruff ME, Hanna LE. Evaluating the prediction of maximal heart rate in children and adolescents. Res Q Exerc Sport 2010; 81/4: 466-471.

31. Welsman A, Armstrong N. Interpreting exercise performance data in relation to body size. In: Armstrong $N$ (ed.). Paediatric Exercise Science and Medicine, 2nd edn. Oxford University Press: Oxford, 2008, 13-19.

32. ACSM. ACSM's Guidelines for Exercise Testing and Prescription, 7th edn. Lippincott Williams and Wilkins: Philadelphia, 2006.

33. Ekelund U, Yngve A, Brage S, Westerterp K, Sjostrom M. Body movement and physical activity energy expenditure in children and adolescents: how to adjust for differences in body size and age. Am J Clin Nutr 2004; 79/5: 851-856.

34. Graves L, Stratton G, Ridgers ND, Cable NT. Comparison of energy expenditure in adolescents when playing new generation and sedentary computer games: cross sectional study. BMJ 2007; 335/7633: 1282-1284.

35. Graf DL, Pratt LV, Hester CN, Short KR. Playing active video games increases energy expenditure in children. Pediatrics 2009; 124/2: 534-540.

36. Hurkmans HL, van den Berg-Emons RJ, Stam HJ. Energy expenditure in adults with cerebral palsy playing Wii sports. Arch Phys Med Rehabil 2010; 91/10: 15771581.

37. Hurkmans HL, Ribbers GM, Streur-Kranenburg MF, Stam HJ, van den Berg-Emons RJ. Energy expenditure in chronic stroke patients playing Wii Sports: a pilot study. J Neuroeng Rehabil 2011; 8/38: Open access document: URL http://www.jneuroengrehab.com/content/8/1/38 38. Nevill AM. The need to scale for differences in body size and mass: an explanation of Kleiber's 0.75 mass exponent. J Appl Physiol 1994; 77/6: 2870-2873.
39. Eagle TF, Gurm R, Goldberg CS, et al. Health status and behavior among middle-school children in a midwest community: what are the underpinnings of childhood obesity? Am Heart J 2010; 160/6: 1185-1189.

40. Strutzenberger G, Richter A, Schneider M, Mundermann A, Schwameder H. Effects of obesity on the biomechanics of stair-walking in children. Gait Posture 2011; 34/1: 119-125.

41. Shultz SP, Sitler MR, Tierney RT, Hillstrom HJ, Song J. Effects of pediatric obesity on joint kinematics and kinetics during 2 walking cadences. Arch Phys Med Rehabil 2009; 90/12: 2146-2154.

42. Shultz SP, Hills AP, Sitler MR, Hillstrom HJ. Body size and walking cadence affect lower extremity joint power in children's gait. Gait Posture 2010; 32/2: 248-252.

43. Graves LE, Ridgers ND, Stratton G. The contribution of upper limb and total body movement to adolescents' energy expenditure whilst playing Nintendo Wii. Eur J Appl Physiol 2008; 104/4: 617-623.

44. Levac D, Pierrynowski MR, Canestraro M, Gurr L, Leonard L, Neeley C. Exploring children's movement characteristics during virtual reality video game play. Hum Mov Sci 2010; 29/6: 1023-1038.

45. Biro FM, Khoury P, Morrison JA. Influence of obesity on timing of puberty. Int J Androl 2006; 29/1: 272-277.

46. McCarney R, Warner J, lliffe S, van Haselen R, Griffin M, Fisher P. The Hawthorne Effect: a randomised, controlled trial. BMC Med Res Methodol 2007; 7/30: Open access document: URL http://www.biomedcentral.com/ $1471-2288 / 7 / 30$

47. Biddiss E, Irwin J. Active video games to promote physical activity in children and youth: a systematic review. Arch Pediatr Adolesc Med 2010; 164/7: 664-672.

48. Declaration of Helsinki, 2008. World Medical Association. [WWW document]. URL http://www.wma.net/e/ ethicsunit/helsinki.htm (accessed January 2013).

49. LMSgrowth, a Microsoft Excel add-in to access growth references based on the LMS method. [WWW document]. URL http://www.healthforallchildren.co.uk/ pro.epl?DO=USERPAGE\&PAGE=Imsdownload (accessed May 2012) 